\title{
A Novel Chaotic System without Equilibrium: Dynamics, Synchronization, and Circuit Realization
}

\author{
Ahmad Taher Azar, ${ }^{1,2}$ Christos Volos, ${ }^{3}$ Nikolaos A. Gerodimos, ${ }^{4}$ George S. Tombras, ${ }^{4}$ \\ Viet-Thanh Pham, ${ }^{5}$ Ahmed G. Radwan, ${ }^{2,6}$ Sundarapandian Vaidyanathan, ${ }^{7}$ \\ Adel Ouannas, ${ }^{8}$ and Jesus M. Munoz-Pacheco ${ }^{9}$ \\ ${ }^{1}$ Faculty of Computers and Information, Benha University, Benha, Egypt \\ ${ }^{2}$ Nanoelectronics Integrated Systems Center (NISC), Nile University, Giza, Egypt \\ ${ }^{3}$ Department of Physics, Aristotle University of Thessaloniki, 54124 Thessaloniki, Greece \\ ${ }^{4}$ Faculty of Physics, Department of Electronics, Computers, Telecommunications and Control, \\ National and Kapodistrian University of Athens, 15784 Athens, Greece \\ ${ }^{5}$ School of Electronics and Telecommunications, Hanoi University of Science and Technology, 01 Dai Co Viet, Hanoi, Vietnam \\ ${ }^{6}$ Engineering Mathematics and Physics, Cairo University, Giza, Egypt \\ ${ }^{7}$ Research and Development Center, Vel Tech University, Avadi, Chennai, Tamil Nadu 600062, India \\ ${ }^{8}$ Laboratory of Mathematics, Informatics and Systems (LAMIS), University of Larbi Tebessi, 12002 Tebessa, Algeria \\ ${ }^{9}$ University of Puebla, Puebla, PUE, Mexico
}

Correspondence should be addressed to Christos Volos; chvolos@gmail.com

Received 21 October 2016; Revised 12 December 2016; Accepted 22 December 2016; Published 2 February 2017

Academic Editor: Carlos Gershenson

Copyright (C) 2017 Ahmad Taher Azar et al. This is an open access article distributed under the Creative Commons Attribution License, which permits unrestricted use, distribution, and reproduction in any medium, provided the original work is properly cited.

A few special chaotic systems without unstable equilibrium points have been investigated recently. It is worth noting that these special systems are different from normal chaotic ones because the classical Shilnikov criterion cannot be used to prove chaos of such systems. A novel unusual chaotic system without equilibrium is proposed in this work. We discover dynamical properties as well as the synchronization of the new system. Furthermore, a physical realization of the system without equilibrium is also implemented to illustrate its feasibility.

\section{Introduction}

A considerable amount of literature has been published on chaotic systems in last decades, for example, Lorenz's system [1], Rössler's system [2], Chen and Ueta's system [3], simple chaotic flows $[4,5]$, memristive chaotic system with heartshaped attractors [6], chaotic circuit based on memristor [7, 8], MOS-transistors based oscillators $[9,10]$, mixed analogdigital designs [11], fully digital realization of chaotic systems $[12,13]$, or electromechanical oscillator [14]. Complexity of chaotic systems has been used in various engineering applications from asymmetric color pathological image encryption $[15,16]$, control and synchronization $[17,18]$, a chaotic video communication scheme via WAN remote transmission [19], and image encryption with avalanche effects [20] to audio encryption scheme [21] and so on.

It is now well established from a variety of studies that equilibrium points play a vital role in our understanding of chaos in nonlinear systems [22-24]. In general, conventional chaotic systems have unstable equilibria and we are able to verify chaos in such systems with the Shilnikov criterion [25, 26]. However, recent researches have consistently shown that chaotic behavior can be observed in three-dimensional (3D) systems with no equilibrium [27].

The study of systems without equilibria has a long history, describing various electromechanical models with rotation 
and electrical circuits with cylindrical phase space. One of the first such examples has been described by Arnold Sommerfeld in 1902 [28], by studying the oscillations caused by a motor driving an unbalanced weight and discovered the resonance capture, which is called "Sommerfeld effect." This phenomenon represents the failure of a rotating mechanical system to be spun up by a torque-limited rotor to a desired rotational velocity due to its resonant interaction with another part of the system [29, 30]. Many decades later, in 198485, Nosé [31] and Hoover [32] have led the study with their proposed dynamical system without equilibria and its various modifications, where hidden chaotic oscillations can be found $[4,33-36]$.

Systematic search routine was developed by Jafari et al. to determine simple quadratic flows with no equilibria [24,27]. Wang and Chen found a new system without equilibrium while studying a chaotic system with any number of equilibria [24]. Wei discovered dynamical properties of a no-equilibrium chaotic system by applying a constant to the Sprott $\mathrm{D}$ system [37]. Multiple attractors in a three-dimensional system with no-equilibrium point were reported in [38]. Akgul et al. designed a random number generator with a 3D chaotic system without equilibrium point [39]. In addition, $4 \mathrm{D}$ noequilibrium systems with hyperchaos were presented in [4042]. It is interesting to note that chaotic systems without equilibrium display "hidden attractors" [43-46]. There has been considerable interest in discovering hidden attractors because they cannot be localized by applying common computational procedures [47-52].

This study makes a contribution to research on systems with hidden attractors by exploring a new chaotic system without equilibrium. In the next section, the description and dynamics of the no-equilibrium system are presented. Synchronization of two new chaotic systems without equilibrium is studied in Section 3. The theoretical system has been realized by an electronic circuit as reported in Section 4 . Finally, conclusion remarks are drawn in the last section.

\section{Description and Dynamics of the System without Equilibrium}

Jafari et al. have introduced an effective approach for investigating potential systems without equilibrium [27]. Authors constructed general models and applied a systematical search routine to obtain seventeen simple flows with no equilibrium [27]. Motivated by Jafari et al.s systems, in this work we consider a general form as follows:

$$
\begin{aligned}
\dot{x}= & y, \\
\dot{y}= & z, \\
\dot{z}= & a_{0}|x|+a_{1} y+a_{2} z+a_{3} y^{2}+a_{4} z^{2}+a_{5} x y+a_{6} x z \\
& +a_{7} y z+a_{8},
\end{aligned}
$$

in which three state variables of the general form are $x, y$, and $z$, while nine parameters are $a_{i}(i=0, \ldots, 8)$ with $a_{0} \neq 0$. An absolute nonlinearity has been included in (1) because it is a potential term for designing nonlinear systems with special characteristics $[53,54]$.

In order to find the equilibrium of system (1), we solve the three following equations:

$$
\begin{aligned}
& y=0, \\
& z=0, \\
& a_{0}|x|+a_{1} y+a_{2} z+a_{3} y^{2}+a_{4} z^{2}+a_{5} x y+a_{6} x z \\
& \quad+a_{7} y z+a_{8}=0 .
\end{aligned}
$$

By substituting (2), (3) into (4), we have

$$
|x|=-\frac{a_{8}}{a_{0}} .
$$

It is easy to verify that the equation is inconsistent for

$$
a_{0} a_{8}>0 \text {. }
$$

In other words, in this case the general model (1) has no equilibrium.

By applying a systematic search procedure [27] into (1), a simple three-dimensional system is obtained in the following form:

$$
\begin{aligned}
& \dot{x}=y, \\
& \dot{y}=z, \\
& \dot{z}=-a|x|-y+3 y^{2}-x z-b,
\end{aligned}
$$

in which three state variables are $x, y$, and $z$ while two positive parameters are $a, b(a>0, b>0)$. According to condition (6), it is trivial to verify that there is no equilibrium in the new system (7).

It is interesting that system (7) can generate chaotic signals although there is the absence of equilibrium. For $a=$ $0.35, b=0.05$ and the initial conditions $(x(0), y(0), z(0))=$ $(0.1,0.1,0.1)$, system (7) generates chaotic behavior as shown in Figure 1. As can be seen in Figure 1, chaotic waveforms and broadband spectra indicate the chaoticity of system (7). In addition, chaotic phase portraits of system (7) are illustrated in Figure 2. Calculated Lyapunov exponents and Kaplan-York dimension of the system without equilibrium (7) are $L_{1}=$ $0,0594, L_{2}=0, L_{3}=-0.358$, and $D_{\mathrm{KY}}=2.1659$, respectively. In other words, system (7) has hidden attractors, which is important for a wide range of scientific and engineering processes [55-58]. In our work, the well-known algorithm of Wolf et al. [59] has been applied to calculate Lyapunov exponents. The time of the computation is 10,000 . It is noted that, due to the different values of the finite-time local Lyapunov exponents and Lyapunov dimension for different points, the maximum of the finite-time local Lyapunov dimensions on the grid of point has to be considered [60-62].

Dynamics of the system without equilibrium have been investigated by changing the value of the bifurcation parameter $a$ in the range from 0.2 to 0.36 . Figures 3 and 4 show the bifurcation diagram and the diagram of maximal Lyapunov exponents (MLEs) of the no-equilibrium system. As can be 


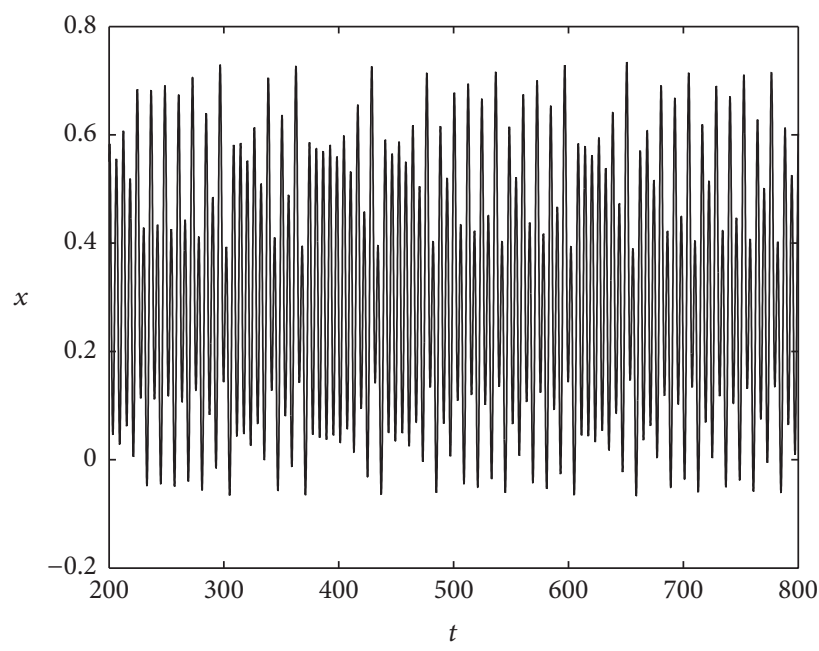

(a)

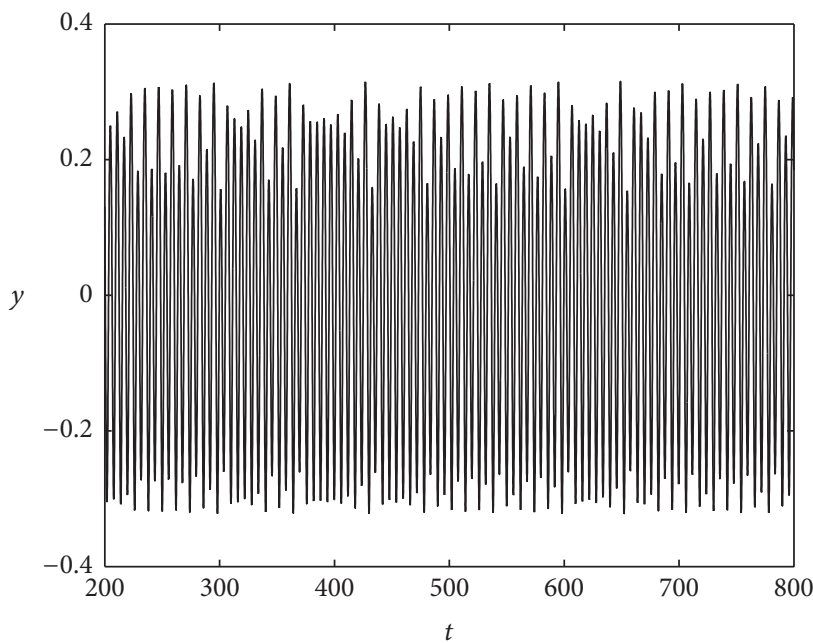

(c)

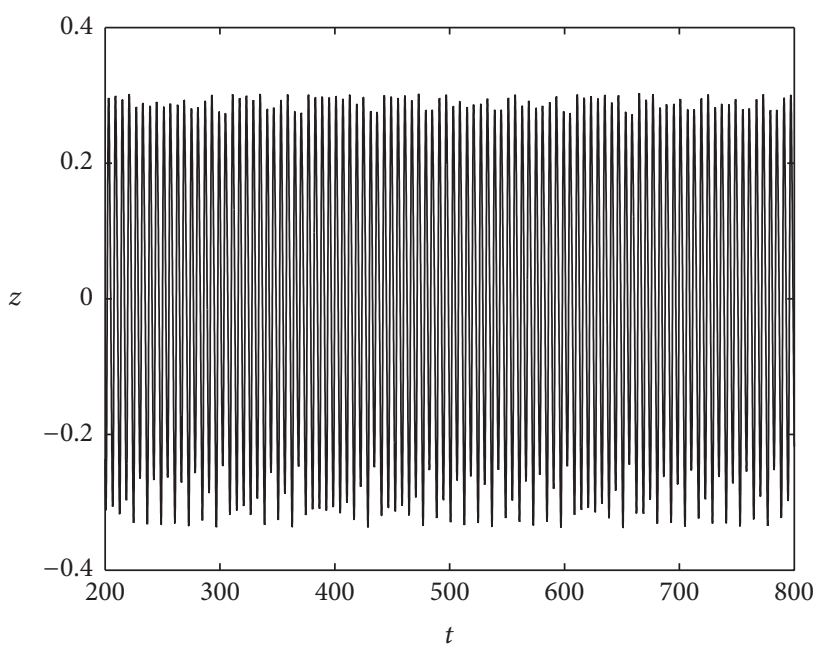

(e)

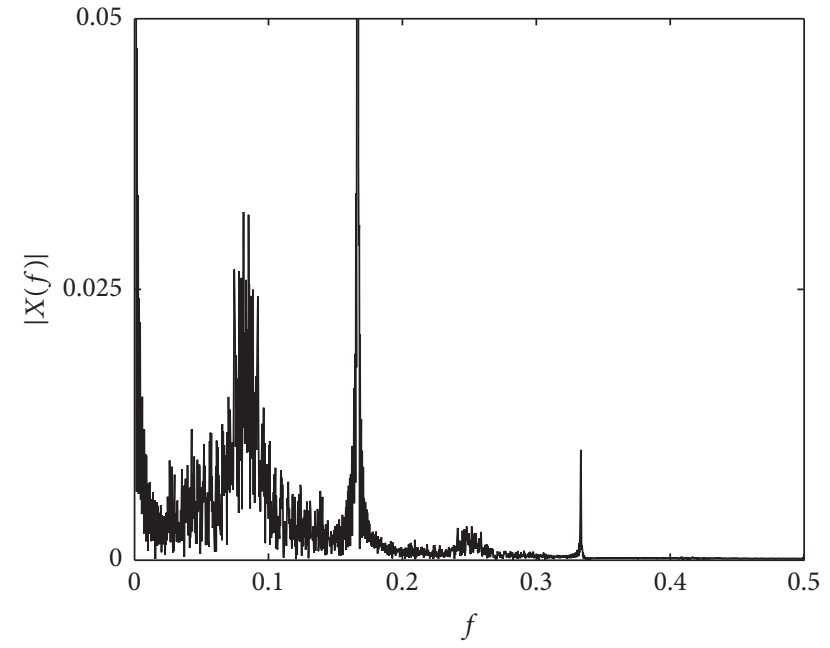

(b)

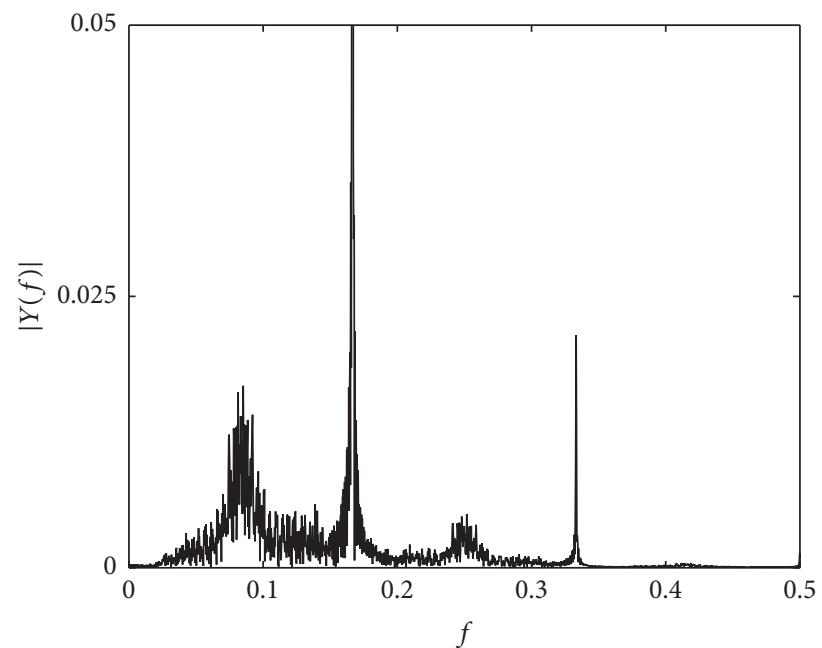

(d)

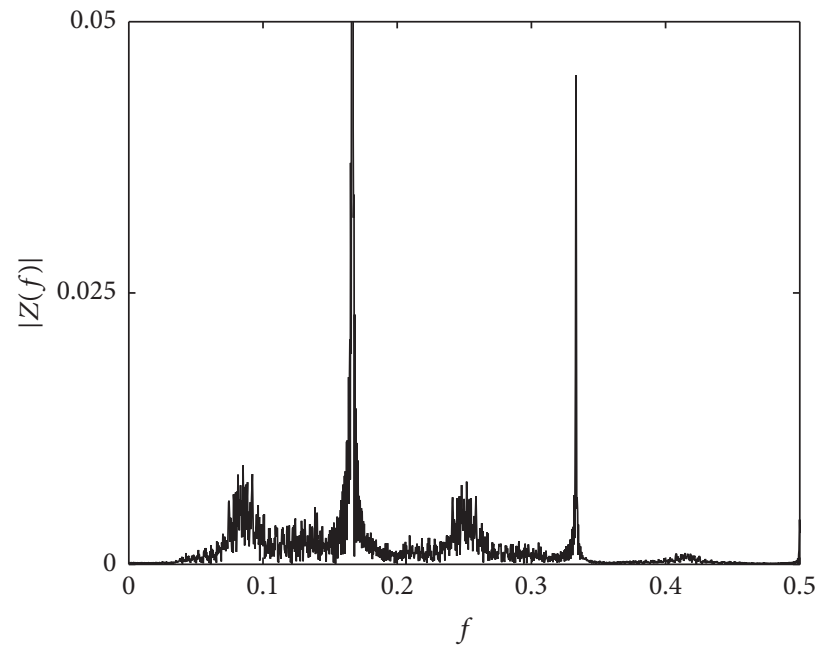

(f)

FIGURE 1: Chaotic waveform and the frequency spectra generated from system (7): (a) time series of $x(t)$, (b) single-sided amplitude spectrum of $x(t)$, (c) time series of $y(t)$, (d) single-sided amplitude spectrum of $y(t)$, (e) time series of $z(t)$, and (f) single-sided amplitude spectrum of $z(t)$. 


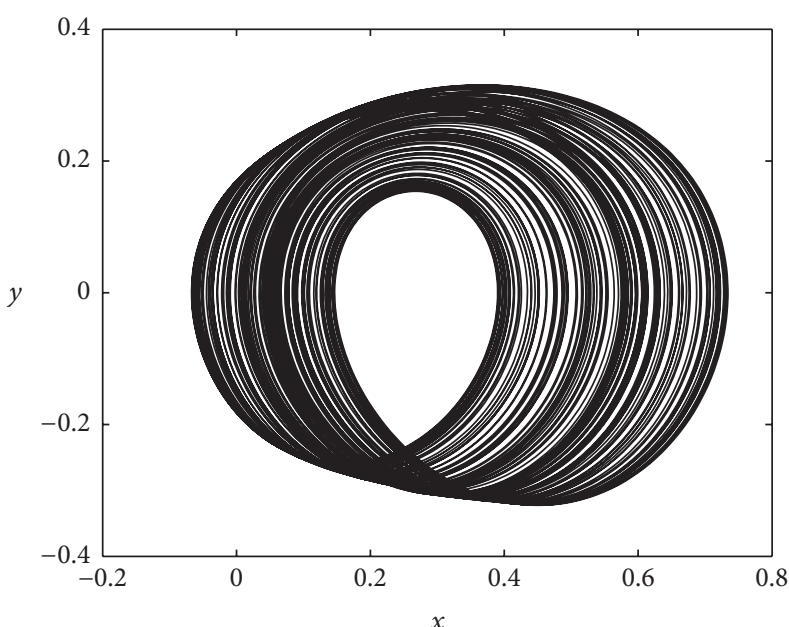

(a)

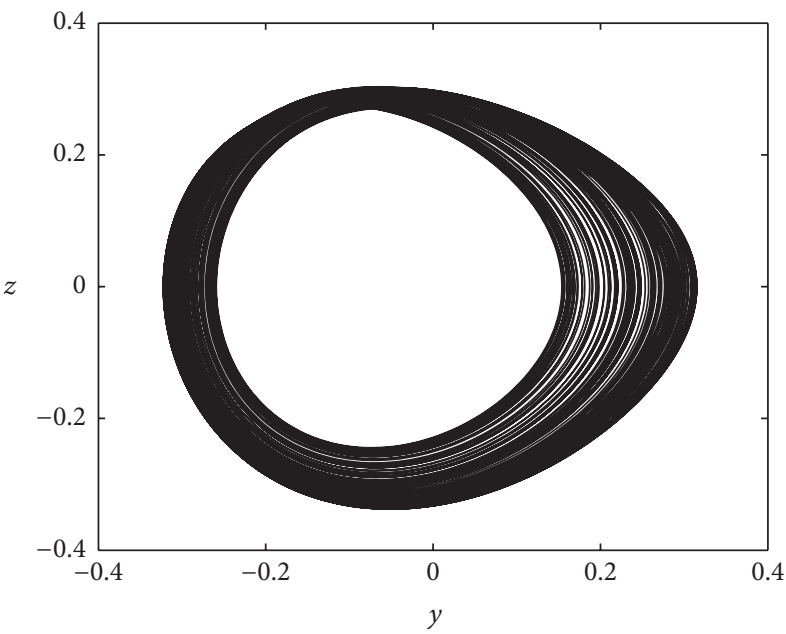

(c)

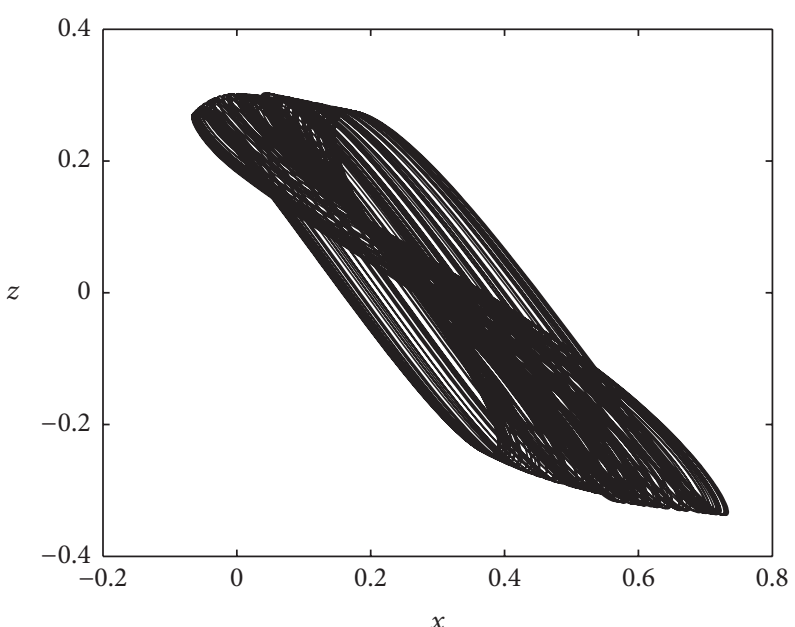

(b)

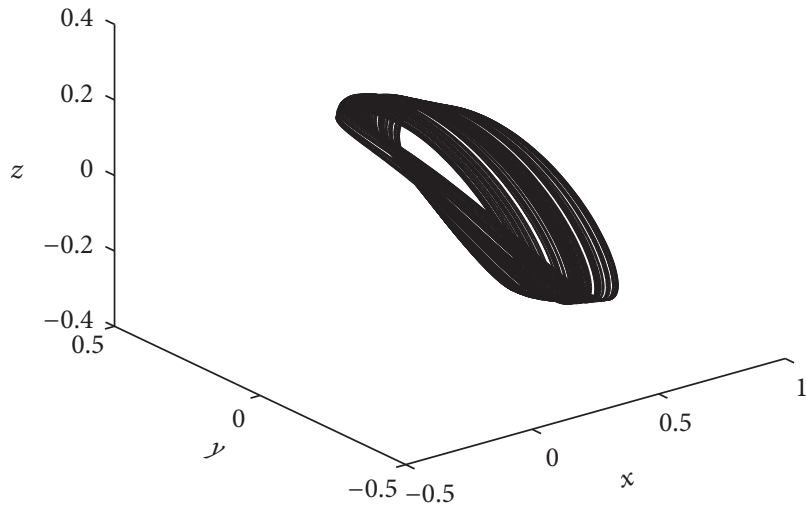

(d)

FiguRE 2: Four views of the chaotic attractors in system without equilibrium (7) in (a) $x-y$ plane, (b) $x-z$ plane, (c) $y-z$ plane, and (d) $x-y-z$ space for $a=0.35, b=0.05$, and the initial conditions $(x(0), y(0), z(0))=(0.1,0.1,0.1)$.

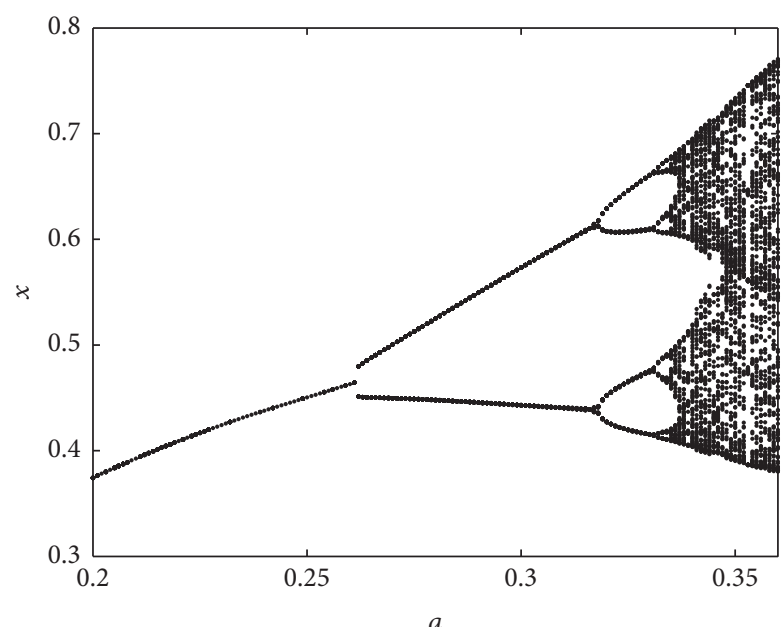

FIGURE 3: Bifurcation diagram of the system without equilibrium (7) for $b=0.05$ and $a \in[0.2,0.36]$.

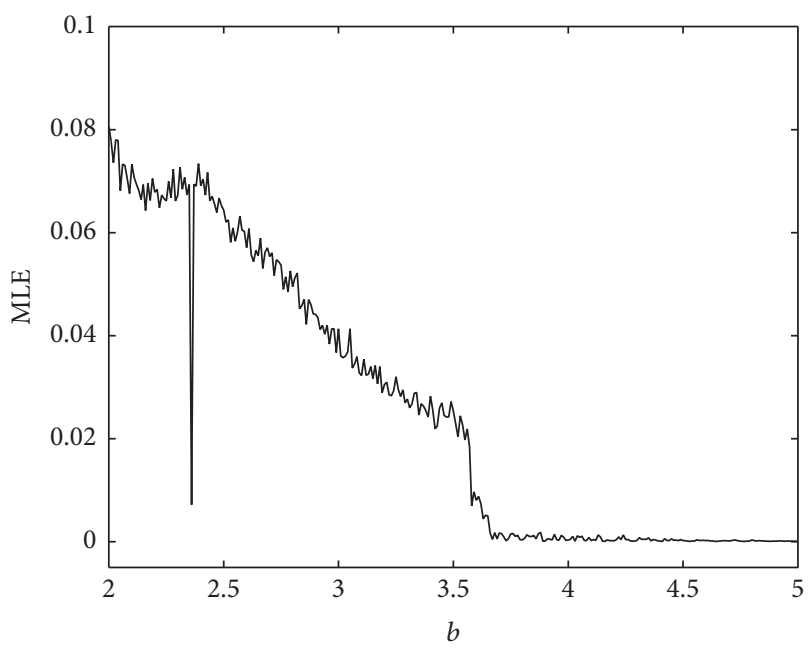

FIGURE 4: Maximum Lyapunov exponents of the system without equilibrium (7) for $b=0.05$ when changing the value of the parameter $a$ from 0.2 to 0.36 . 


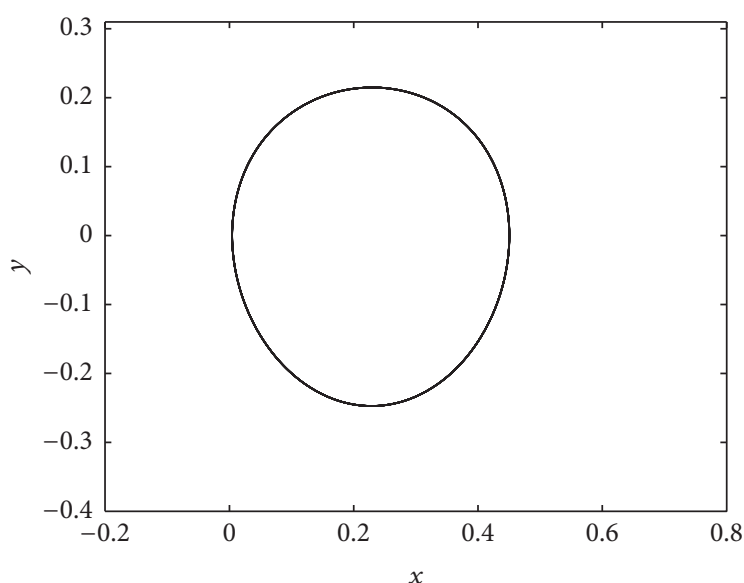

(a)

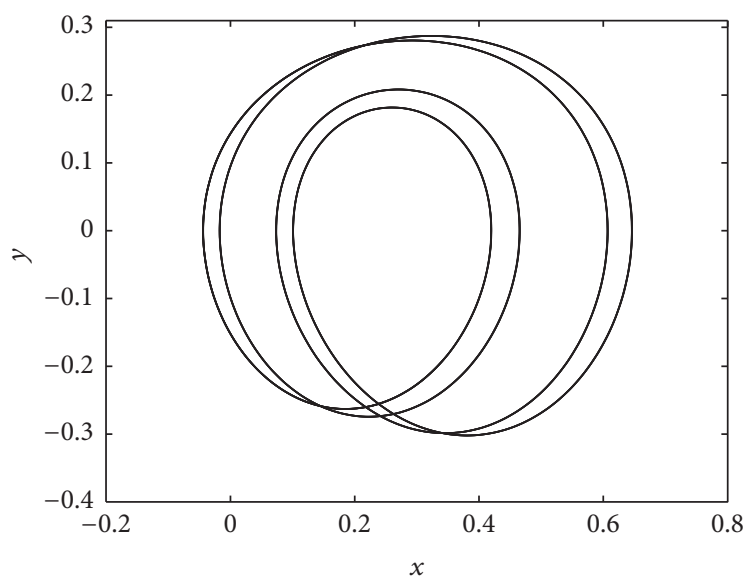

(c)

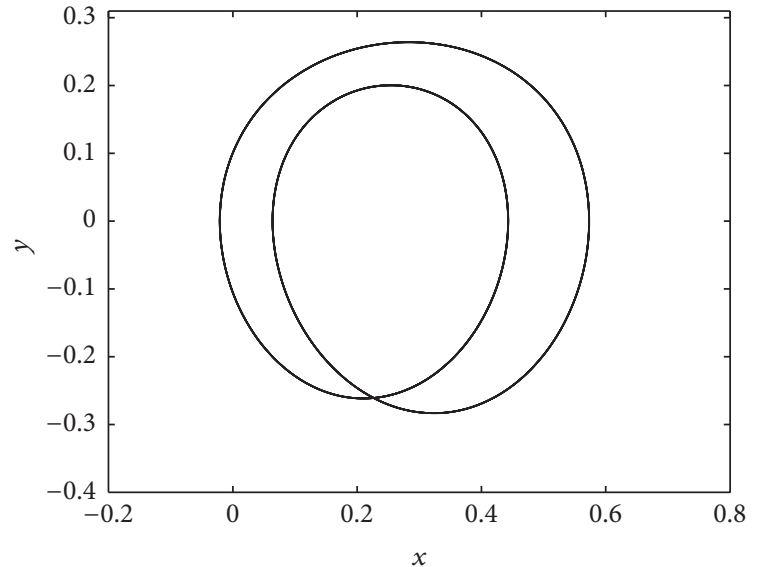

(b)

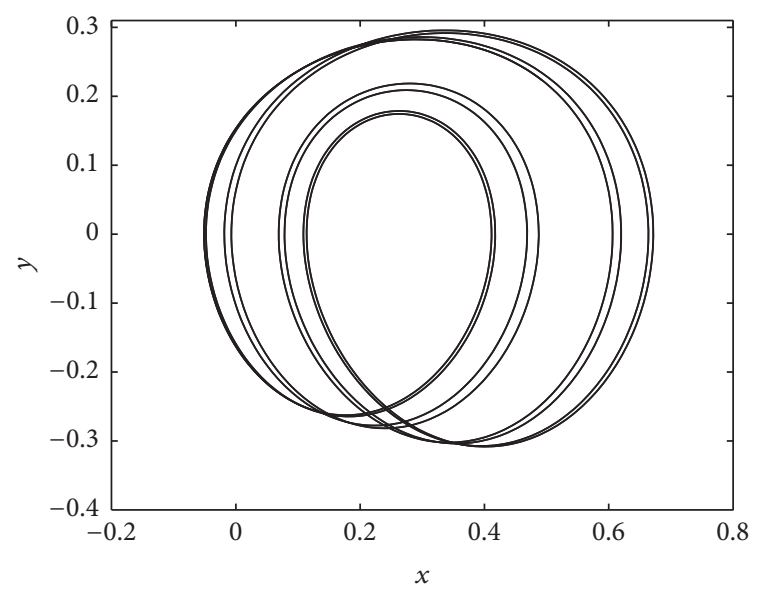

(d)

FIGURE 5: Four views of limit cycles in the system without equilibrium (7) in (a) period-1 oscillation $(a=0.25)$, (b) period-2 oscillation $(a=$ $0.3)$, (c) period-4 oscillation $(a=0.325)$, and (d) period-8 oscillation $(a=0.333)$ for the initial conditions $(x(0), y(0), z(0))=(0.1,0.1,0.1)$ and $b=0.05$.

seen from Figures 3 and 4, system (7) displays periodical oscillations for $a<0.335$. For instance, different periodical oscillations of system (7) are illustrated in Figure 5. For $a \geq$ 0.335 , complex behaviors of the system can be observed. Moreover, it is easy to verify the presence of a perioddoubling route to chaos when increasing the value of the parameter $a$.

\section{Synchronization of Two Identical Systems without Equilibrium}

The past decade has seen the rapid development of synchronization schemes for numerous chaotic systems because synchronization plays a critical role in practical applications [63-67]. Therefore, when investigating a new chaotic system it is important to consider its synchronization ability. In this section, we study the synchronization of two new systems without equilibrium (the master and slave systems) via an adaptive controller, which has been reported as an effective approach [68-70]. by

Here the master system without equilibrium is presented

$$
\begin{aligned}
& \dot{x}_{1}=y_{1}, \\
& \dot{y}_{1}=z_{1}, \\
& \dot{z}_{1}=-a\left|x_{1}\right|-y_{1}+3 y_{1}^{2}-x_{1} z_{1}-b,
\end{aligned}
$$

where three state variables are $x_{1}, y_{1}$, and $z_{1}$ and the unknown system parameters are $a, b$. The slave system without equilibrium is given by

$$
\begin{aligned}
& \dot{x}_{2}=y_{2}+u_{x}, \\
& \dot{y}_{2}=z_{2}+u_{y}, \\
& \dot{z}_{2}=-a\left|x_{2}\right|-y_{2}+3 y_{2}^{2}-x_{2} z_{2}-b+u_{z},
\end{aligned}
$$

in which $x_{2}, y_{2}$, and $z_{2}$ are system's variables and $\mathbf{u}=\left[u_{x}, u_{y}\right.$, $\left.u_{z}\right]^{T}$ is an adaptive control. By calculating the difference 
between the slave system and the master system, the state errors are defined as

$$
\begin{aligned}
& e_{x}=x_{2}-x_{1}, \\
& e_{y}=y_{2}-y_{1}, \\
& e_{z}=z_{2}-z_{1} .
\end{aligned}
$$

As a result, the state error dynamics are calculated by

$$
\begin{aligned}
& \dot{e}_{x}=\dot{x}_{2}-\dot{x}_{1}, \\
& \dot{e}_{y}=\dot{y}_{2}-\dot{y}_{1}, \\
& \dot{e}_{z}=\dot{z}_{2}-\dot{z}_{1} .
\end{aligned}
$$

The parameter estimation error is denoted as $e_{a}$

$$
e_{a}=a-\widehat{a},
$$

where the estimation of the unknown parameter $(a)$ is $\widehat{a}$. By differentiating (12), we get

$$
\dot{e}_{a}=-\dot{\hat{a}} .
$$

We design an adaptive control to synchronize the slave system without equilibrium (9) with the master system (8) without equilibrium as follows:

$$
\begin{aligned}
u_{x}= & -e_{y}-k_{x} e_{x} \\
u_{y}= & -e_{z}-k_{y} e_{y}, \\
u_{z}= & e_{y}-3\left(y_{2}^{2}-y_{1}^{2}\right)+x_{2} z_{2}-x_{1} z_{1}+\widehat{a}\left(\left|x_{2}\right|-\left|x_{1}\right|\right) \\
& -k_{z} e_{z} .
\end{aligned}
$$

In the adaptive control (14), three positive gain constants are $k_{x}, k_{y}$, and $k_{z}$ while the parameter update law is constructed by

$$
\dot{\hat{a}}=e_{z}\left(\left|x_{1}\right|-\left|x_{2}\right|\right) \text {. }
$$

It is simple to verify that the slave system (9) and the master system (8) are synchronized when applying the proposed adaptive control (14). We prove this result by using the selected Lyapunov function:

$$
V\left(e_{x}, e_{y}, e_{z}, e_{a}\right)=\frac{1}{2}\left(e_{x}^{2}+e_{y}^{2}+e_{z}^{2}+e_{a}^{2}\right) .
$$

From (16), we have the differentiation of $V$ :

$$
\dot{V}=e_{x} \dot{e}_{x}+e_{y} \dot{e}_{y}+e_{z} \dot{e}_{z}+e_{a} \dot{e}_{a} .
$$

By combining (8), (9), and (14), synchronization error dynamics are achieved as

$$
\begin{aligned}
& \dot{e}_{x}=-k_{x} e_{x}, \\
& \dot{e}_{y}=-k_{y} e_{y}, \\
& \dot{e}_{z}=-e_{a}\left(\left|x_{2}\right|-\left|x_{1}\right|\right)-k_{z} e_{z} .
\end{aligned}
$$

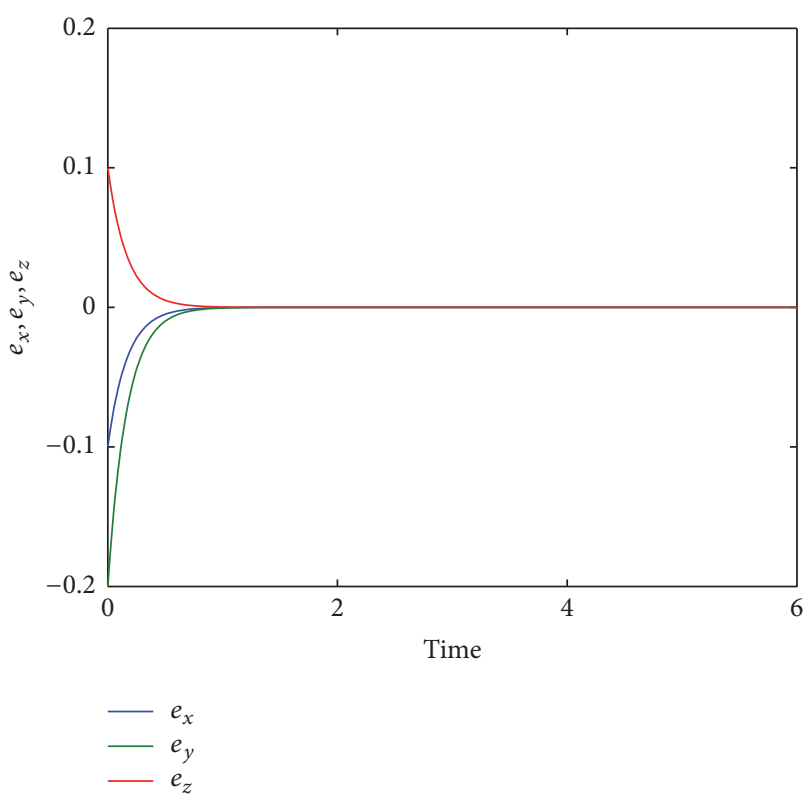

FIGURE 6: Time-history of the synchronization errors between the slave system without equilibrium (9) and the master system without equilibrium (8).

Finally, by substituting (13) and (18) into (17), the differentiation of the Lyapunov function can be simplified as

$$
\dot{V}=-k_{x} e_{x}^{2}-k_{y} e_{y}^{2}-k_{z} e_{z}^{2} .
$$

Obviously, the differentiation of $V$ is a negative semidefinite function. Therefore, according to Barbalat's lemma [71], we have $e_{x} \rightarrow 0, e_{y} \rightarrow 0$, and $e_{z} \rightarrow 0$ exponentially as $t \rightarrow \infty$. As a result, the synchronization between the slave system (9) and the master system (8) is verified.

In order to confirm the calculation of the synchronization scheme, we consider an example where the parameter values of the master system and the slave system are fixed as

$$
\begin{aligned}
& a=0.35, \\
& b=0.05 .
\end{aligned}
$$

The initial states of the master system are assumed as

$$
\begin{aligned}
& x_{1}(0)=0.1, \\
& y_{1}(0)=0.1, \\
& z_{1}(0)=0.1,
\end{aligned}
$$

while the initial states of the slave system are selected as

$$
\begin{aligned}
& x_{2}(0)=0, \\
& y_{2}(0)=-0.1, \\
& z_{2}(0)=0.2 .
\end{aligned}
$$

We take the positive gain constants which are $k_{x}=6, k_{y}=$ 6 , and $k_{z}=6$ and set the initial condition of the parameter estimate, that is,

$$
\widehat{a}(0)=0.3 .
$$

The time-history of the synchronization errors $e_{x}, e_{y}, e_{z}$ is reported in Figure 6. Furthermore, the time series of the 
master and the slave systems are illustrated in Figure 7. From Figures 6 and 7 it is straightforward to see the synchronization of the slave system and the master system.

\section{Realization of the Proposed System without Equilibrium}

The issue of realizing theoretical chaotic models has received considerable critical attention due to its practical applications [65, 72-76]. Thus, an electronic circuit for realizing the proposed system without equilibrium (7) is introduced in this section. We rescaled three state variables of system without equilibrium (7), that is, $X=10 x, Y=10 y$, and $Z=10 z$, to get enough larger signals in our electronic circuit. Therefore, the system without equilibrium (7) is transformed into the following equivalent system:

$$
\begin{aligned}
& \dot{X}=Y, \\
& \dot{Y}=Z, \\
& \dot{Z}=-a|X|-Y+\frac{3}{10} Y^{2}-\frac{1}{10} X Z-10 b .
\end{aligned}
$$

Figure 8 shows the schematic of the circuit for realizing system (24). As shown in Figure 8, there are three integrators $\left(U_{3}-U_{5}\right)$ implemented with operational amplifiers. The circuit of absolute nonlinearity $(|X|)$ is based on two operational amplifiers $\left(U_{6}, U_{7}\right)$ and two diodes $\left(D_{1}, D_{2}\right)$. By applying Kirchhoff's circuit laws into the designed circuit, the following circuital equation is derived:

$$
\begin{aligned}
\dot{X} & =\frac{1}{R C} Y, \\
\dot{Y} & =\frac{1}{R C} Z, \\
\dot{Z} & \\
& =\frac{1}{R C}\left(-\frac{R}{R_{a}}|X|-Y+\frac{R}{R_{1} 10 V} Y^{2}-\frac{1}{10 V} X Z-V_{b}\right) .
\end{aligned}
$$

The variables $X, Y$, and $Z$ in (25) correspond to the voltages in the outputs of three integrators $\left(U_{3}, U_{4}\right.$, and $\left.U_{5}\right)$, respectively. It is simple to verify that system (25) is equivalent to the system without equilibrium (24) by normalizing it with $\tau=t / R C$. In order to get $a=0.35$ and $b=0.05$, the electronic components have been selected as $R=10 \mathrm{k} \Omega$, $R_{a}=28.571 \mathrm{k} \Omega, R_{1}=3.333 \mathrm{k} \Omega, C=10 \mathrm{nF}$, and $V_{b}=$ $0.5 \mathrm{~V}_{\mathrm{DC}}$. The power supplies of all active devices are $\pm 15 \mathrm{~V}_{\mathrm{DC}}$. Implementation of the circuit on a breadboard is shown in Figure 9. We have measured signals in the real circuit by using oscilloscope. Experimental results are reported in Figure 10, which display a good agreement with numerical results in Figure 2.

\section{Conclusions}

The present study provides an additional system without equilibrium, which has received significant attention in

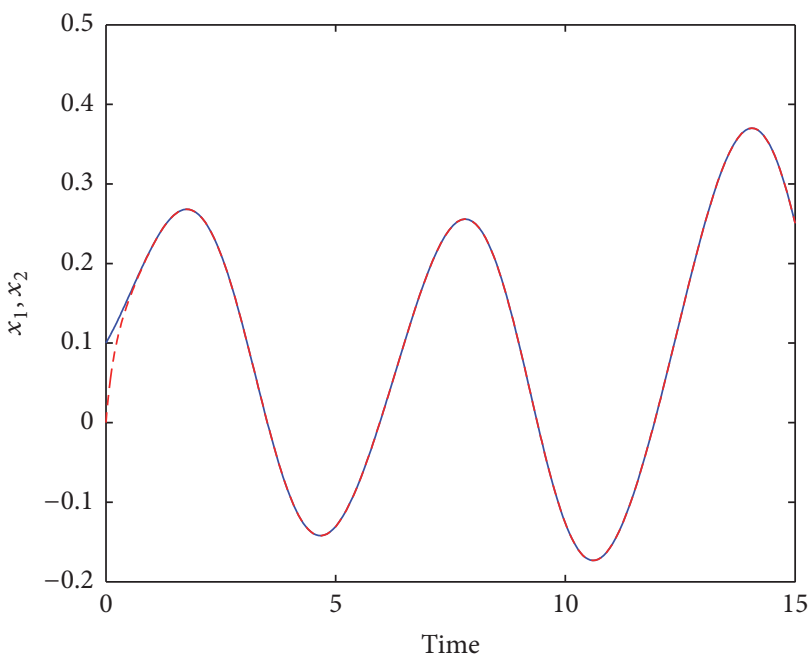

(a)

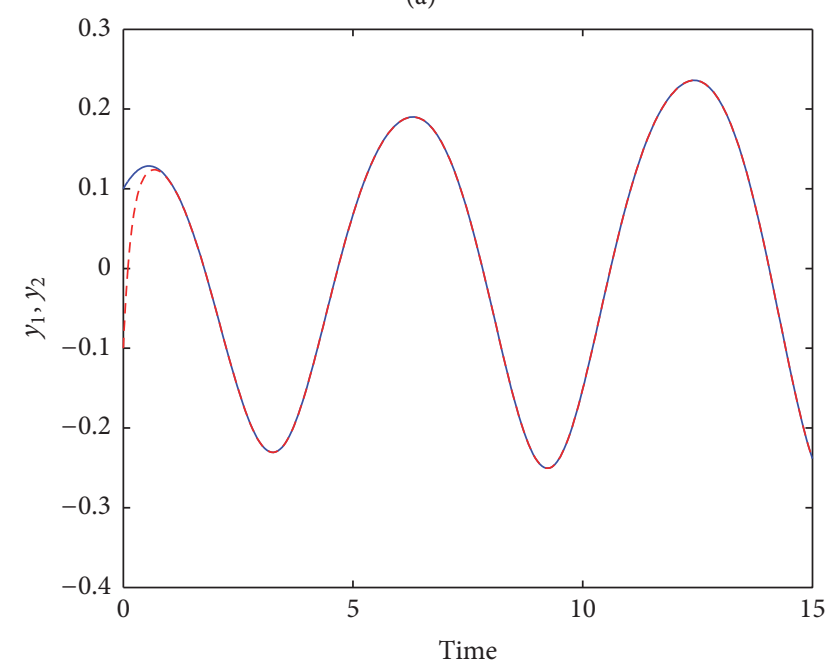

(b)

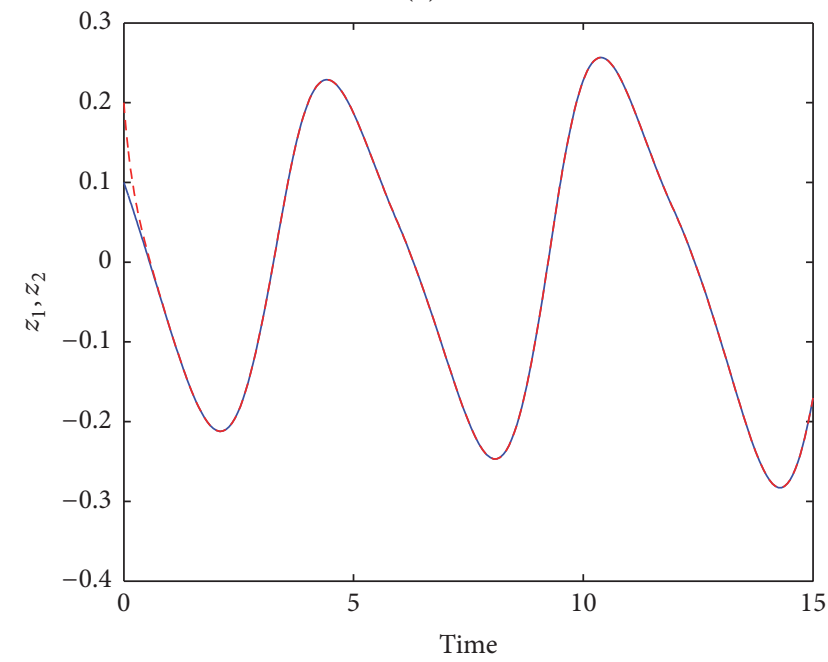

(c)

FIgURE 7: Time series of the master system (blue solid) and the slave systems (red dashed): (a) $x_{1}$ and $x_{2}$, (b) $y_{1}$ and $y_{2}$, and (c) $z_{1}$ and $z_{2}$.

the research community recently. Dynamics of the proposed system are studied by numerical tools and physical 

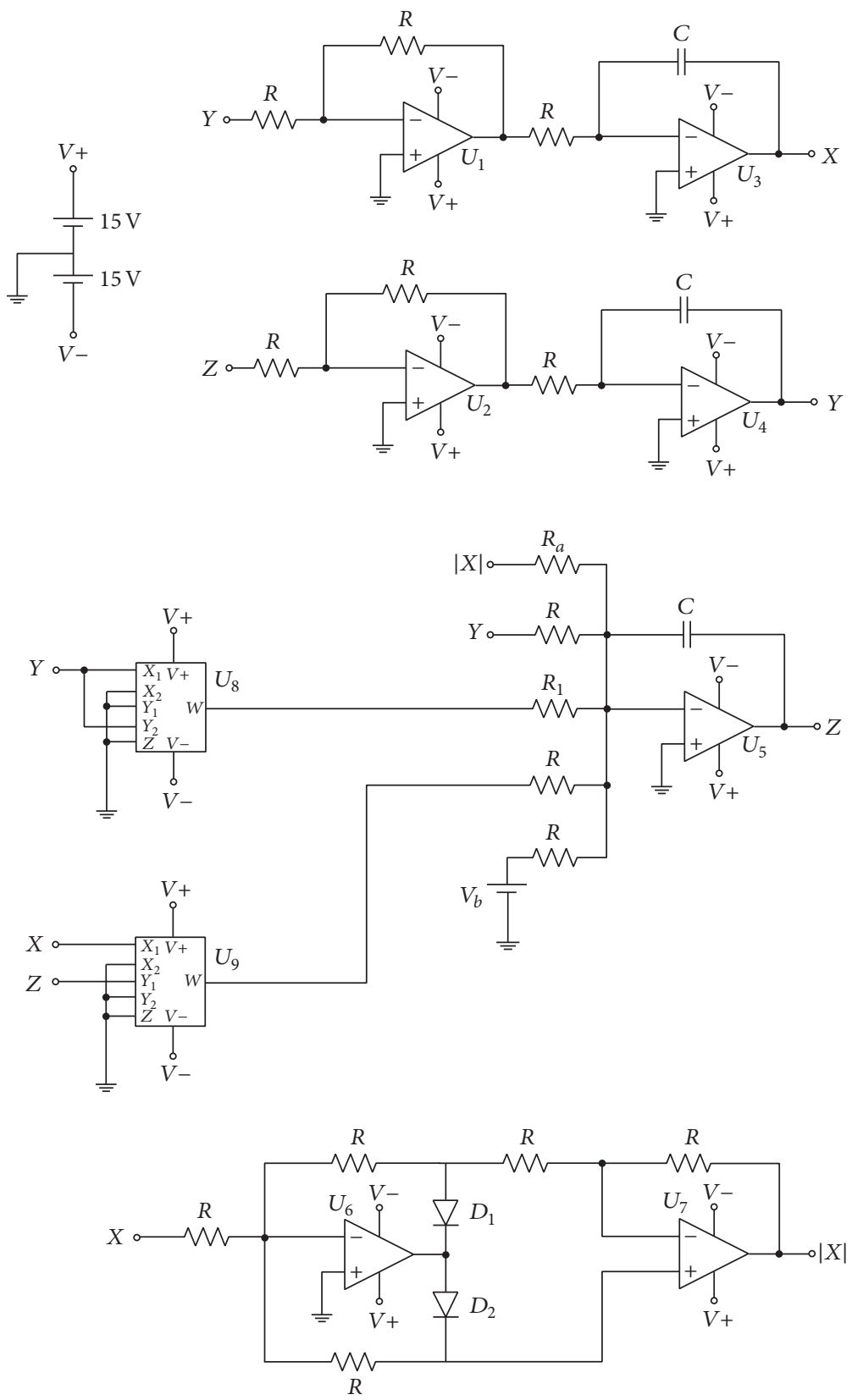

FIGURE 8: Schematic of the circuit including 16 resistors, seven operational amplifiers, two analog multipliers, two diodes, and three capacitors.

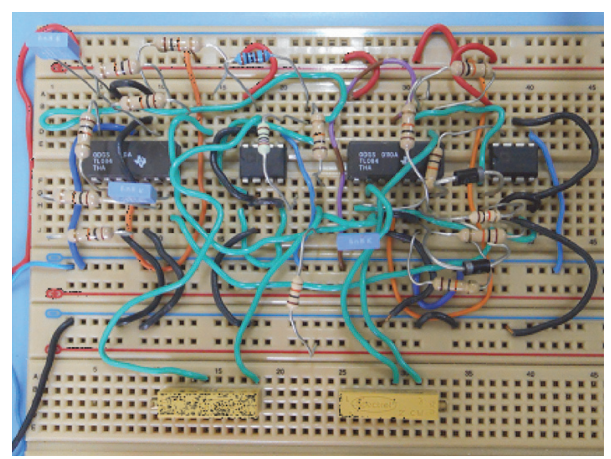

FIGURE 9: Physical realization of the theoretical system by using common electronic components. 


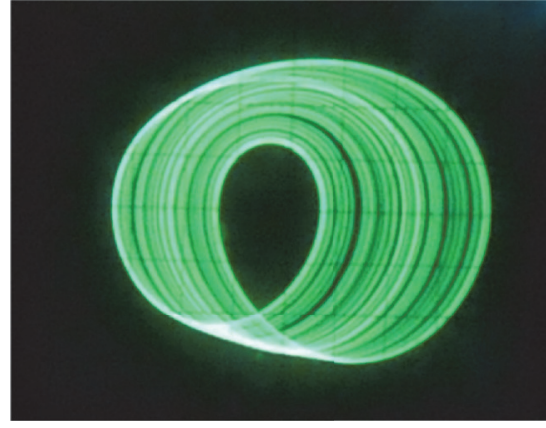

(a)

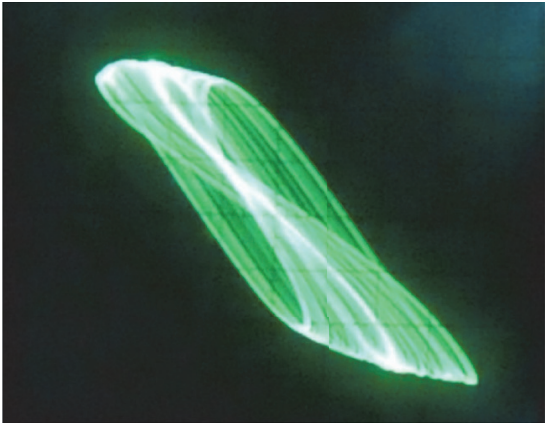

(b)

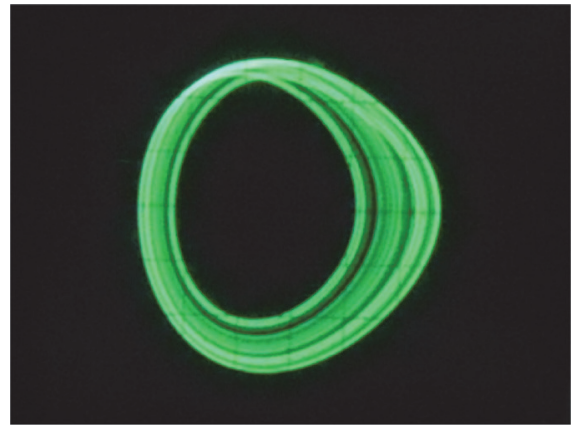

(c)

FIgURE 10: Captured chaotic attractors of the designed circuit in (a) $X-Y$ plane, (b) $X-Z$ plane, and (c) $Y-Z$ plane.

implementation. It is interesting that the system can generate chaotic signals despite the fact that there is an absence of equilibrium. The system is realized easily by using common electronic components; therefore, it would be interesting to assess the practical application of the new system. Further studies related to the possible real-time applications of the system will be investigated in our future works.

\section{Competing Interests}

The authors declare that there is no conflict of interests regarding the publication of this paper.

\section{Acknowledgments}

The authors acknowledge Professor GuanRong Chen, Department of Electronic Engineering, City University of Hong Kong, for suggesting many helpful references.

\section{References}

[1] E. Lorenz, "Deterministic nonperiodic flow," Journal of the Atmospheric Sciences, vol. 20, pp. 130-141, 1963.

[2] O. Rössler, "An equation for continuous chaos," Physics Letters A, vol. 57, pp. 397-398, 1976.

[3] G. Chen and T. Ueta, "Yet another chaotic attractor," International Journal of Bifurcation and Chaos in Applied Sciences and Engineering, vol. 9, no. 7, pp. 1465-1466, 1999.

[4] J. C. Sprott, "Some simple chaotic flows," Physical Review E, vol. 50, no. 2, pp. R647-R650, 1994.

[5] J. C. Sprott, Elegant Chaos Algebraically Simple Chaotic Flows, World Scientific, Singapore, 2010.

[6] J. Wu, L. Wang, G. Chen, and S. Duan, "A memristive chaotic system with heart-shaped attractors and its implementation," Chaos, Solitons \& Fractals, vol. 92, pp. 20-29, 2016.

[7] R. Wu and C. Wang, "A new simple chaotic circuit based on memristor," International Journal of Bifurcation and Chaos in Applied Sciences and Engineering, vol. 26, no. 9, Article ID 1650145, 11 pages, 2016.

[8] A. G. Radwan, K. Moaddy, and I. Hashim, "Amplitude modulation and synchronization of fractional-order memristor-based Chua's circuit," Abstract and Applied Analysis, vol. 2013, Article ID 758676, 10 pages, 2013.
[9] A. G. Radwan, A. M. Soliman, and A.-L. El-Sedeek, "An inductorless CMOS realization of Chua's circuit," Chaos, Solitons and Fractals, vol. 18, no. 1, pp. 149-158, 2003.

[10] A. G. Radwan, A. M. Soliman, and A.-L. El-Sedeek, "MOS realization of the conjectured simplest chaotic equation," Circuits, Systems, and Signal Processing, vol. 22, no. 3, pp. 277-285, 2003.

[11] A. Radwan, A. Soliman, and A. S. Elwakil, "1-D digitallycontrolled multiscroll chaos generator," International Journal of Bifurcation and Chaos, vol. 17, no. 1, pp. 227-242, 2007.

[12] M. A. Zidan, A. G. Radwan, and K. N. Salama, "Controllable Vshape multiscroll butterfly attractor: system and circuit implementation," International Journal of Bifurcation and Chaos, vol. 22, no. 6, Article ID 1250143, 2012.

[13] A. S. Mansingka, M. Affan Zidan, M. L. Barakat, A. G. Radwan, and K. N. Salama, "Fully digital jerk-based chaotic oscillators for high throughput pseudo-random number generators up to 8.77 Gbits/s," Microelectronics Journal, vol. 44, no. 9, pp. 744752, 2013.

[14] A. Buscarino, C. Famoso, L. Fortuna, and M. Frasca, "A new chaotic electro-mechanical oscillator," International Journal of Bifurcation and Chaos in Applied Sciences and Engineering, vol. 26, no. 10, Article ID 1650161, 7 pages, 2016.

[15] H. Liu, A. Kadir, and Y. Li, "Asymmetric color pathological image encryption scheme based on complex hyper chaotic system," Optik, vol. 127, pp. 5812-5819, 2016.

[16] A. G. Radwan, S. H. AbdElHaleem, and S. K. Abd-El-Hafiz, "Symmetric encryption algorithms using chaotic and nonchaotic generators: a review," Journal of Advanced Research, vol. 7, no. 2, pp. 193-208, 2016.

[17] K. Moaddy, A. G. Radwan, K. N. Salama, S. Momani, and I. Hashim, "The fractional-order modeling and synchronization of electrically coupled neuron systems," Computers \& Mathematics with Applications, vol. 64, no. 10, pp. 3329-3339, 2012.

[18] A. G. Radwan, K. Moaddy, K. N. Salama, S. Momani, and I. Hashim, "Control and switching synchronization of fractional order chaotic systems using active control technique," Journal of Advanced Research, vol. 5, no. 1, pp. 125-132, 2014.

[19] Z. Lin, S. Yu, C. Li, J. Lü, and Q. Wang, "Design and smartphonebased implementation of a chaotic video communication scheme via WAN remote transmission," International Journal of Bifurcation and Chaos in Applied Sciences and Engineering, vol. 26, no. 9, Article ID 1650158, 8 pages, 2016.

[20] L. Min, X. Yang, G. Chen, and D. Wang, "Some polynomial chaotic maps without equilibria and an application to image 
encryption with avalanche effects," International Journal of Bifurcation and Chaos, vol. 25, no. 9, Article ID 1550124, 2015.

[21] H. Liu, A. Kadir, and Y. Li, "Audio encryption scheme by confusion and diffusion based on multi-scroll chaotic system and one-time keys," Optik, vol. 127, no. 19, pp. 7431-7438, 2016.

[22] J. Lü and G. Chen, "Generating multiscroll chaotic attractors: theories, methods and applications," International Journal of Bifurcation and Chaos in Applied Sciences and Engineering, vol. 16, no. 4, pp. 775-858, 2006.

[23] X. Wang and G. Chen, "A chaotic system with only one stable equilibrium," Communications in Nonlinear Science and Numerical Simulation, vol. 17, no. 3, pp. 1264-1272, 2012.

[24] X. Wang and G. Chen, "Constructing a chaotic system with any number of equilibria," Nonlinear Dynamics, vol. 71, no. 3, pp. 429-436, 2013.

[25] L. P. Shilnikov, "A case of the existence of a countable number of periodic motions," Soviet Mathematics. Doklady, vol. 6, pp. 163-166, 1965.

[26] L. Shilnikov, A. Shilnikov, D. Turaev, and L. Chua, Methods of Qualitative Theory in Nonlinear Dynamics, World Scientific, Singapore, 1998.

[27] S. Jafari, J. C. Sprott, and S. M. R. H. Golpayegani, "Elementary quadratic chaotic flows with no equilibria," Physics Letters A, vol. 377, no. 9, pp. 699-702, 2013.

[28] A. Sommerfeld, "Beitrage zum dynamischen ausbau der festigkeitslehre," Zeitschrift des Vereins Deutscher Ingenieure, vol. 46, pp. 391-394, 1902.

[29] R. Evan-Iwanowski, Resonance Oscillations in Mechanical Systems, Elsevier, Amsterdam, The Netherlands, 1976.

[30] M. Eckert, Arnold Sommerfeld: Science, Life and Turbulent Times 1868-1951, Springer, New York, NY, USA, 2013.

[31] S. Nosé, "A molecular dynamics method for simulations in the canonical ensemble," Molecular Physics, vol. 52, no. 2, pp. 255268, 1984.

[32] W. G. Hoover, "Canonical dynamics: equilibrium phase-space distributions," Physical Review A, vol. 31, no. 3, pp. 1695-1697, 1985.

[33] H. A. Posch, W. G. Hoover, and F. J. Vesely, "Canonical dynamics of the Nosé oscillator: stability, order, and chaos," Physical Review. A. Third Series, vol. 33, no. 6, pp. 4253-4265, 1986.

[34] J. C. Sprott, W. G. Hoover, and C. G. Hoover, "Heat conduction, and the lack thereof, in time-reversible dynamical systems: generalized Nosé-Hoover oscillators with a temperature gradient," Physical Review E, vol. 89, no. 4, Article ID 042914, 2014.

[35] J. C. Sprott, "Strange attractors with various equilibrium types," European Physical Journal: Special Topics, vol. 224, no. 8, pp. 1409-1419, 2015.

[36] L. Wang and X.-S. Yang, "The invariant tori of knot type and the interlinked invariant tori in the Nosè-Hoover oscillator," The European Physical Journal B, vol. 88, article 78, 5 pages, 2015.

[37] Z. Wei, "Dynamical behaviors of a chaotic system with no equilibria," Physics Letters A, vol. 376, no. 2, pp. 102-108, 2011.

[38] J.-L. Zuo and C.-L. Li, "Multiple attractors and dynamic analysis of a no-equilibrium chaotic system," Optik, vol. 127, no. 19, pp. 7952-7957, 2016.

[39] A. Akgul, H. Calgan, I. Koyuncu, I. Pehlivan, and A. Istanbullu, "Chaos-based engineering applications with a 3D chaotic system without equilibrium points," Nonlinear Dynamics, vol. 84, no. 2, pp. 481-495, 2016.
[40] Z. Wang, S. Cang, E. O. Ochola, and Y. Sun, "A hyperchaotic system without equilibrium," Nonlinear Dynamics. An International Journal of Nonlinear Dynamics and Chaos in Engineering Systems, vol. 69, no. 1-2, pp. 531-537, 2012.

[41] Z. Wei, R. Wang, and A. Liu, "A new finding of the existence of hidden hyperchaotic attractors with no equilibria," Mathematics and Computers in Simulation, vol. 100, pp. 13-23, 2014.

[42] Z. Wang, J. Ma, S. Cang, Z. Wang, and Z. Chen, "Simplified hyper-chaotic systems generating multi-wing non-equilibrium attractors," Optik, vol. 127, no. 5, pp. 2424-2431, 2016.

[43] G. A. Leonov, N. V. Kuznetsov, O. A. Kuznetsova, S. M. Seledzhi, and V. I. Vagaitsev, "Hidden oscillations in dynamical systems," WSEAS Transactions on Systems and Control, vol. 6, no. 2, pp. 54-67, 2011.

[44] G. A. Leonov, N. V. Kuznetsov, and V. I. Vagaitsev, "Localization of hidden Chua's attractors," Physics Letters. A, vol. 375, no. 23, pp. 2230-2233, 2011.

[45] T. Kapitaniak and G. A. Leonov, "Multistability: uncovering hidden attractors," European Physical Journal: Special Topics, vol. 224, no. 8, pp. 1405-1408, 2015.

[46] D. Dudkowski, S. Jafari, T. Kapitaniak, N. V. Kuznetsov, G. A. Leonov, and A. Prasad, "Hidden attractors in dynamical systems," Physics Reports, vol. 637, pp. 1-50, 2016.

[47] G. A. Leonov, N. V. Kuznetsov, and V. I. Vagaitsev, "Hidden attractor in smooth Chua systems," Physica D. Nonlinear Phenomena, vol. 241, no. 18, pp. 1482-1486, 2012.

[48] G. A. Leonov and N. V. Kuznetsov, "Hidden attractors in dynamical systems: From hidden oscillation in HilbertKolmogorov, Aizerman and Kalman problems to hidden chaotic attractor in Chua circuits," International Journal of Bifurcation and Chaos in Applied Sciences and Engineering, vol. 23, no. 1, Article ID 1330002, 69 pages, 2013.

[49] G. A. Leonov, N. V. Kuznetsov, M. A. Kiseleva, E. P. Solovyeva, and A. M. Zaretskiy, "Hidden oscillations in mathematical model of drilling system actuated by induction motor with a wound rotor," Nonlinear Dynamics, vol. 77, no. 1-2, pp. 277-288, 2014.

[50] G. A. Leonov, N. V. Kuznetsov, and T. N. Mokaev, "Hidden attractor and homoclinic orbit in Lorenz-like system describing convective fluid motion in rotating cavity," Communications in Nonlinear Science and Numerical Simulation, vol. 28, no. 1-3, pp. 166-174, 2015.

[51] Q. Li, H. Zeng, and J. Li, "Hyperchaos in a 4D memristive circuit with infinitely many stable equilibria," Nonlinear Dynamics. An International Journal of Nonlinear Dynamics and Chaos in Engineering Systems, vol. 79, no. 4, pp. 2295-2308, 2015.

[52] S. Brezetskyi, D. Dudkowski, and T. Kapitaniak, "Rare and hidden attractors in Van der Pol-Duffing oscillators," The European Physical Journal Special Topics, vol. 224, no. 8, pp. 1459-1467, 2015.

[53] B. Munmuangsaen, J. C. Sprott, W. J. Thio, A. Buscarino, and L. Fortuna, "A simple chaotic flow with a continuously adjustable attractor dimension," International Journal of Bifurcation and Chaos in Applied Sciences and Engineering, vol. 25, no. 12, Article ID 1530036, 2015.

[54] C. Li, J. C. Sprott, Z. Yuan, and H. Li, "Constructing chaotic systems with total amplitude control," International Journal of Bifurcation and Chaos, vol. 25, no. 10, Article ID 1530025, 2015.

[55] A. Chudzik, P. Perlikowski, A. Stefanski, and T. Kapitaniak, "Multistability and rare attractors in van der pol-duffing oscillator," International Journal of Bifurcation and Chaos in Applied Sciences and Engineering, vol. 21, no. 7, pp. 1907-1912, 2011. 
[56] P. R. Sharma, M. D. Shrimali, A. Prasad, N. V. Kuznetsov, and G. A. Leonov, "Control of multistability in hidden attractors," European Physical Journal: Special Topics, vol. 224, no. 8, pp. 1485-1491, 2015.

[57] Z. T. Zhusubaliyev, E. Mosekilde, A. N. Churilov, and A. Medvedev, "Multistability and hidden attractors in an impulsive Goodwin oscillator with time delay," European Physical Journal: Special Topics, vol. 224, no. 8, pp. 1519-1539, 2015.

[58] Z. T. Zhusubaliyev and E. Mosekilde, "Multistability and hidden attractors in a multilevel DC/DC converter," Mathematics and Computers in Simulation, vol. 109, pp. 32-45, 2015.

[59] A. Wolf, J. B. Swift, H. L. Swinney, and J. A. Vastano, "Determining Lyapunov exponents from a time series," Physica D: Nonlinear Phenomena, vol. 16, no. 3, pp. 285-317, 1985.

[60] N. V. Kuznetsov, "The Lyapunov dimension and its estimation via the Leonov method," Physics Letters A, vol. 380, no. 25-26, pp. 2142-2149, 2016.

[61] N. V. Kuznetsov, T. A. Alexeeva, and G. A. Leonov, "Invariance of LYApunov exponents and LYApunov dimension for regular and irregular linearizations," Nonlinear Dynamics. An International Journal of Nonlinear Dynamics and Chaos in Engineering Systems, vol. 85, no. 1, pp. 195-201, 2016.

[62] G. A. Leonov, N. V. Kuznetsov, N. A. Korzhemanova, and D. V. Kusakin, "Lyapunov dimension formula for the global attractor of the Lorenz system," Communications in Nonlinear Science and Numerical Simulation, vol. 41, pp. 84-103, 2016.

[63] S. Banerjee, Chaos Synchronization and Cryptography for Secure Communication, IGI Global, Hershey, Pa, USA, 2010.

[64] J. L. Mata-Machucaa, R. Martínez-Guerraa, R. Aguilar-Lópezb, and C. Aguilar-Ibañez, "A chaotic system in synchronization and secure communications," Communications in Nonlinear Science and Numerical Simulation, vol. 17, no. 4, pp. 1706-1713, 2012.

[65] C. K. Volos, I. M. Kyprianidis, and I. N. Stouboulos, "Image encryption process based on chaotic synchronization phenomena," Signal Processing, vol. 93, no. 5, pp. 1328-1340, 2013.

[66] R. Aguilar-López, R. Martínez-Guerra, and C. A. PerezPinacho, "Nonlinear observer for synchronization of chaotic systems with application to secure data transmission," The European Physical Journal Special Topics, vol. 223, no. 8, pp. 1541-1548, 2014.

[67] S. Çiçek, A. Ferikoğlu, and I. Pehlivan, "A new 3D chaotic system: dynamical analysis, electronic circuit design, active control synchronization and chaotic masking communication application," Optik, vol. 127, no. 8, pp. 4024-4030, 2016.

[68] C. Hua and X. Guan, "Adaptive control for chaotic systems," Chaos, Solitons \&amp; Fractals, vol. 22, no. 1, pp. 55-60, 2004.

[69] G. Feng and G. Chen, "Adaptive control of discrete-time chaotic systems: a fuzzy control approach," Chaos, Solitons \& Fractals, vol. 23, no. 2, pp. 459-467, 2005.

[70] S.-Y. Li, C.-H. Yang, C.-T. Lin, L.-W. Ko, and T.-T. Chiu, "Adaptive synchronization of chaotic systems with unknown parameters via new backstepping strategy," Nonlinear Dynamics, vol. 70, no. 3, pp. 2129-2143, 2012.

[71] H. K. Khalil, Nonlinear Systems, Prentice Hall, Upper Saddle River, NJ, USA, 3rd edition, 2002.

[72] M. s. Yalcin, J. A. Suykens, and J. Vandewalle, "True random bit generation from a double-scroll attractor," IEEE Transactions on Circuits and Systems. I. Regular Papers, vol. 51, no. 7, pp. 13951404, 2004.
[73] G. Y. Wang, X. L. Bao, and Z. L. Wang, "Design and implementation of a new hyperchaotic system," Chinese Physics B, vol. 17, pp. 3596-3602, 2008.

[74] C. K. Volos, I. M. Kyprianidis, and I. N. Stouboulos, "A chaotic path planning generator for autonomous mobile robots," Robotics and Autonomous Systems, vol. 60, no. 4, pp. 651-656, 2012.

[75] D. Valli, B. Muthuswamy, S. Banerjee et al., "Synchronization in coupled Ikeda delay systems experimental observations using Field Programmable Gate Arrays," The European Physical Journal Special Topics, vol. 223, pp. 1465-1479, 2014.

[76] A. Akgul, I. Moroz, I. Pehlivan, and S. Vaidyanathan, "A new four-scroll chaotic attractor and its engineering applications," Optik, vol. 127, no. 13, pp. 5491-5499, 2016. 


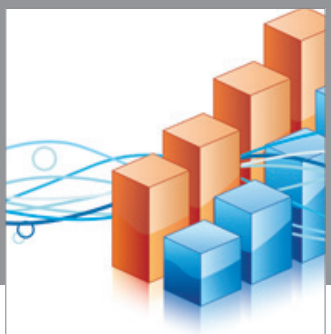

Advances in

Operations Research

vatem alat4

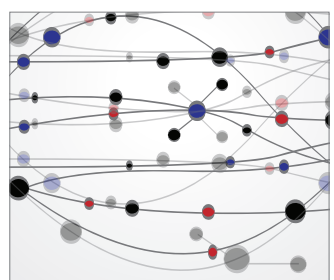

\section{The Scientific} World Journal
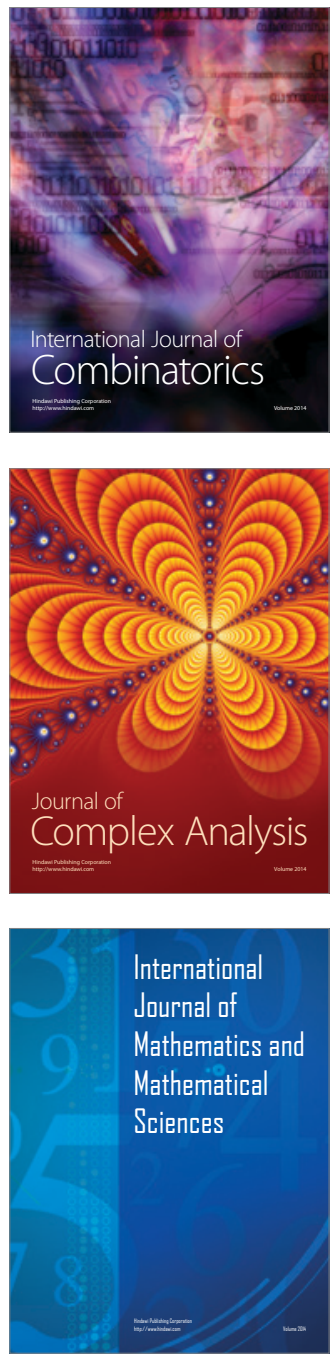
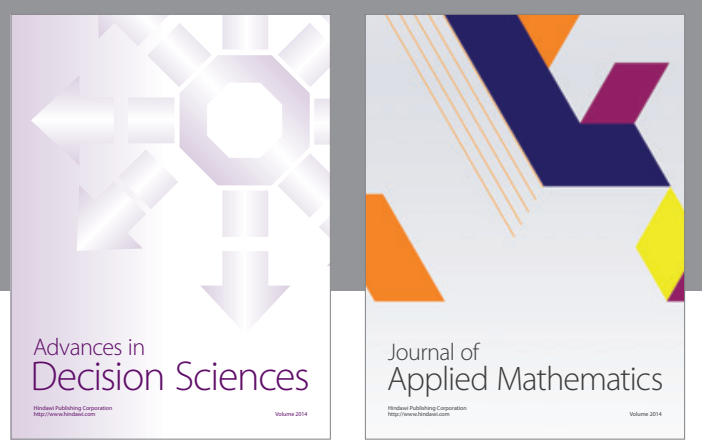

Algebra

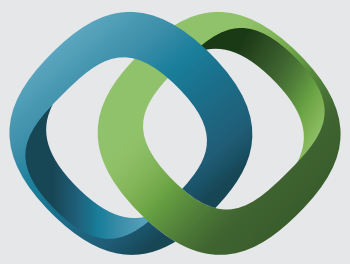

\section{Hindawi}

Submit your manuscripts at

https://www.hindawi.com
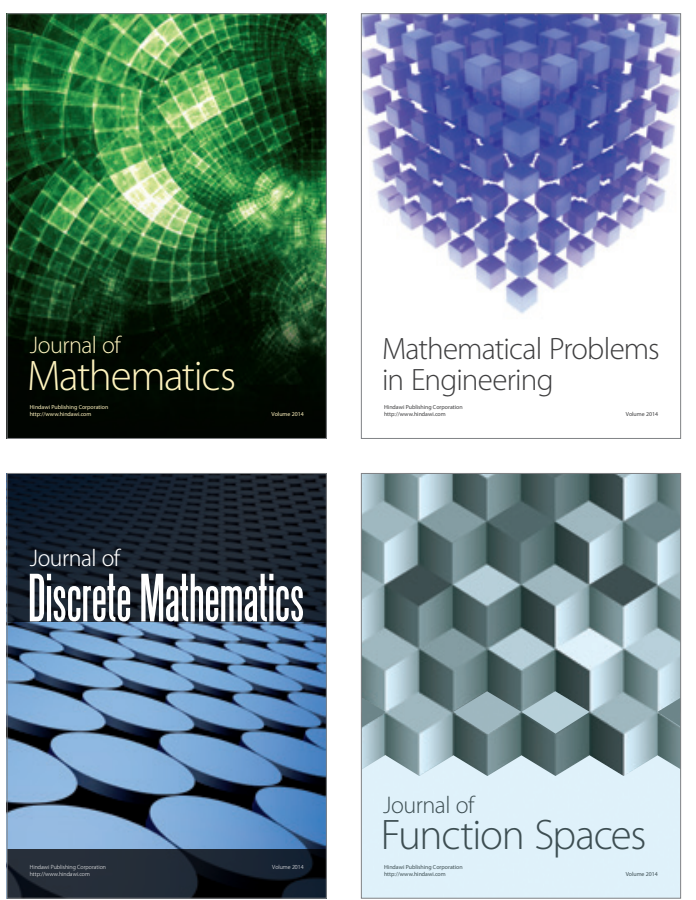

Mathematical Problems in Engineering
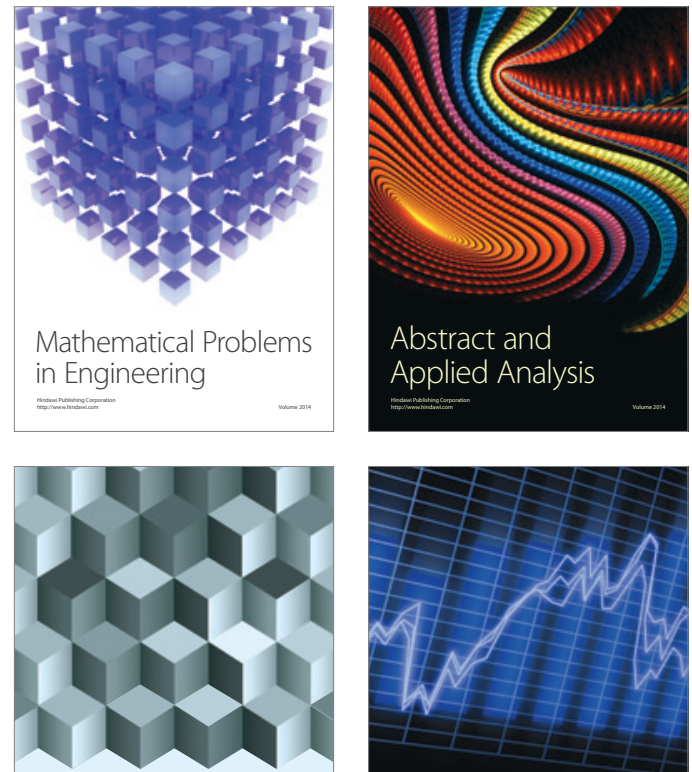

Journal of

Function Spaces

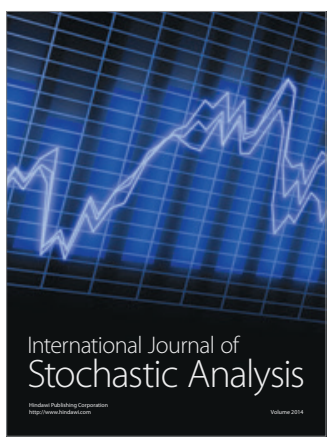

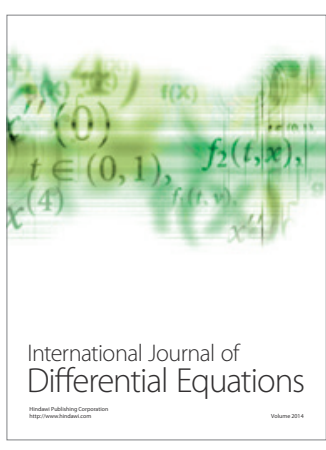
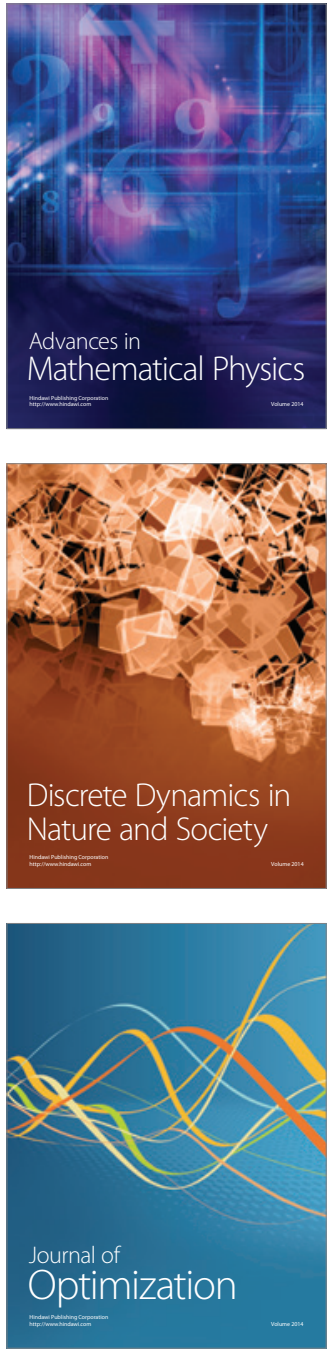